\title{
GREEN SYNTHESIS OF SILVER NANOPARTICLES USING ROASTED COFFEA ARABICA BEAN EXTRACT AND ITS ANTIMICROBIAL ACTIVITY
}

\author{
Tejaswini R, Dr Anisa Athar \\ Department of Microbiology \\ Government Science College \\ Nrupathunga road, Bangalore, India
}

\begin{abstract}
An extract obtained from roasted Coffea arabica bean was used as bio-reductant and mixed with standard $\mathrm{AgNO}_{3}(0.1 \mathrm{M})$ solution. The formation of silver nanoparticles(AgNP) was observed by the change in the colour of the solution (coffee extract $+\mathrm{AgNO}_{3}$ ) from brown to blackish brown. UV-vis spectrophotometry analysis showed maximum adsorption at $240 \mathrm{~nm}$. The SEM analysis showed the morphology of the AgNPs as oval and spherical and the sized of the particles between the range of $25 \mathrm{~nm}$ to $51 \mathrm{~nm}$. The crystalline size of the AgNPs was analyzed between the range of $10 \mathrm{~nm}$ to $30 \mathrm{~nm}$ employing XRD technique. The antimicrobial activity study of the synthesized silver nanoparticles showed zone of inhibition against the clinically important bacteria namely- E coli, Pseudomonas, Klebsiella, Staphylococcus and Bacillus.
\end{abstract}

KEY WORDS: Coffee extract, $\mathrm{AgNO}_{3}$, silver nanoparticle, characterization, antimicrobial activity.

\section{INTRODUCTION}

Nanaparticles are particles between 1 to 100 nanometres scale in size and its physical and chemical properties differ from the ones of the bulk material. According to the National Institute of Health of America, nanotechnology is defined as "the creation of functional materials, devices or systems through control of matter at a scale of 1-100 $\mathrm{nm}$ and the exploitation of novel properties and phenomena at this scale". The metal nanoparticles have applications in diagnostics, biomarkers, cell labeling, contrast agents for biological imaging, antimicrobial agents, drug delivery systems and nano-drugs for treatment of various diseases. Likewise, silver nanoparticles are widely used in medical field as antimicrobials, sterilizers and testing tools for diagnosing and detecting sensitive biomolecules.
Various methods like reduction reaction, chemical and photochemical reaction, thermal decomposition, radiation assisted method, electrochemical process, sono-chemical and microwave assisted synthesis have been used for the synthesis of AgNPs successfully. But these methods are not ecofriendly as these involve the use of toxic and hazardous chemicals and more over the end product requires various purification steps to obtain pure AgNPs.

Green synthesis approach for the synthesis of AgNPs is best as it does not involve the use of any toxic chemicals, is economical, environmentally friendly, simple zero energy based and less timeconsuming process. This method involves various biological materials such as plant extracts, bacteria, actinomycetes, fungi and enzymes are used as the bio-reductants. These bio-reductants reduce silver ions to silver nano particles (AgNPs).

In this experiment a study was conducted on the synthesis of AgNPs using the extract of roasted Coffea arabica (coffee) seeds and also the antimicrobial activity of synthesized AgNPs referring an experiment conducted by Dhand Vivek et.al., (2015), with tittle- 'Green synthesis of silver nanoparticles using Coffea arabica seed extract and its antimicrobial activity'.

\section{MATERIALS AND METHODS}

1.Roasted Coffea arabica bean extract preparation:

Roasted Coffea arabica (coffee) beans were grinded using an electric mixer to make a fine powder. $10 \mathrm{~g}$ of this powder was taken in a conical flask along with $100 \mathrm{ml}$ of distilled water and the mixture was heated at $60^{\circ} \mathrm{C}$ for 30 minutes in a heating mantle and filter by Whatman No. 1 filter paper. This filtered extract was further used as bioreductant for the synthesis of AgNPs. 


\section{Synthesis of silver nanoparticles (AgNPs):}

The obtained extract of Coffea arabica from above step was mixed with $0.1 \mathrm{M} \mathrm{AgNO}_{3}$ solution (in ratio of $1: 1)$ in a conical flask and kept on a shaker incubator until the color change was observed from brown to blackish brown indicating formation of AgNPs.

\section{Characterisation:}

The characterization of the SNPs was carried out using UV spectrophotometer, SEM (scanning electron microscope) and XRD (X-ray diffraction).

UV spectrum of SNP were recorded between the range from 200 to $600 \mathrm{~nm}$.

For SEM and XRD analysis, 100microlitre of AgNPs sample was flooded onto a $1 \mathrm{~cm}^{2}$ slide and dried by keeping it in hot air oven overnight. SEM was employed to measure the size and analyze shape of nanoparticles and XRD was employed to analyze the composition of the synthetized nanoparticles.

\section{Antimicrobial activity of the synthesized AgNPs:}

The antimicrobial activity of the synthesized AgNPs was carried out by disc diffusion method. Different nutrient agar plates were inoculated with clinically important bacteria such as Escherichia coli, Pseudomonas, Klebsiella, Staphylococcus and Bacillus. Sterile discs containing $5 \mu \mathrm{l}$ silver nanoparticle solution each is placed on the agar surface of these plates and incubated for 24 hours at $37^{\circ} \mathrm{C}$. After incubation the plates were observed for zone of inhibition.

\section{RESULTS}

\section{Green synthesis of AgNPs using roasted Coffea} arabica bean extract:

Formation of AgNPs due to the reduction of silver ions by the roasted Coffea arabica bean extract was observed by the change in the color from brown to blackish brown in the solution $\left(\mathrm{AgNO}_{3}+\right.$ coffee extract in 1:1 ratio) within 20 minutes.

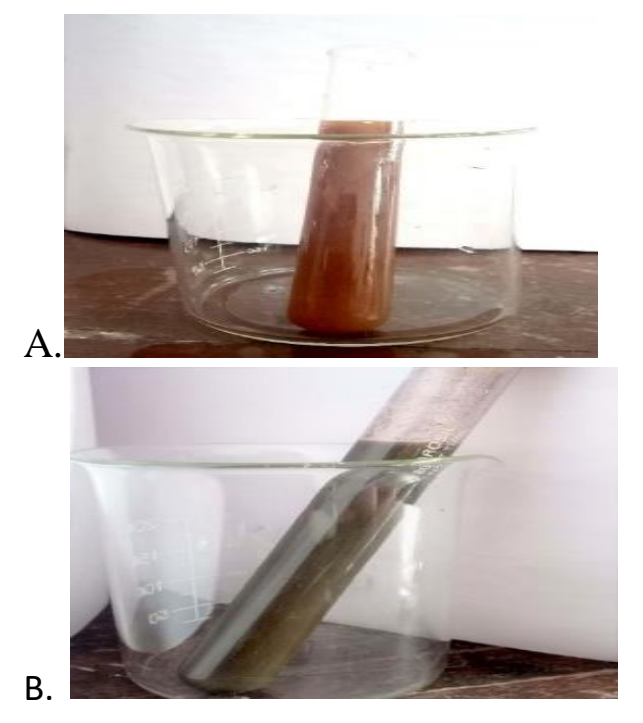

A. Before reduction of $\mathbf{A g}^{2+}$ (brown); B. After reduction of $\mathrm{Ag}^{2+}$ (blackish brown)

\section{UV spectrophotometer analysis:}

The UV spectrophotometer analysis of the AgNPs sample showed the maximum absorption at $240 \mathrm{~nm}$. The absorbance pattern obtained is shown in the Figure.

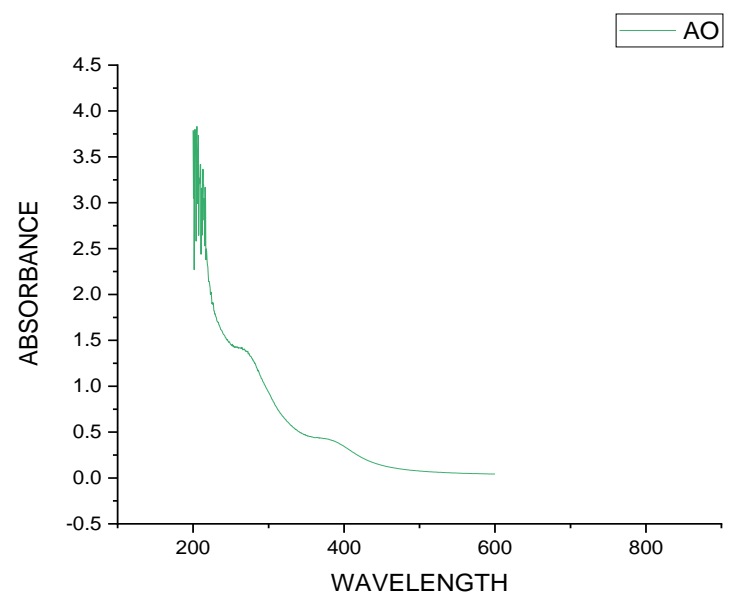

Figure of UV spectroscopy pattern

\section{SEM analysis:}

The SEM (scanning electron microscope) technique was used to analyze the particle shape and size of the synthesized silver nanoparticles. From this analysis, the shape of the nanoparticles obtained was found to be oval and spherical and the size $25 \mathrm{~nm}$ to $51 \mathrm{~nm}$. 
International Journal of Engineering Applied Sciences and Technology, 2021

Vol. 5, Issue 11, ISSN No. 2455-2143, Pages 299-303

Published Online March 2021 in IJEAST (http://www.ijeast.com)

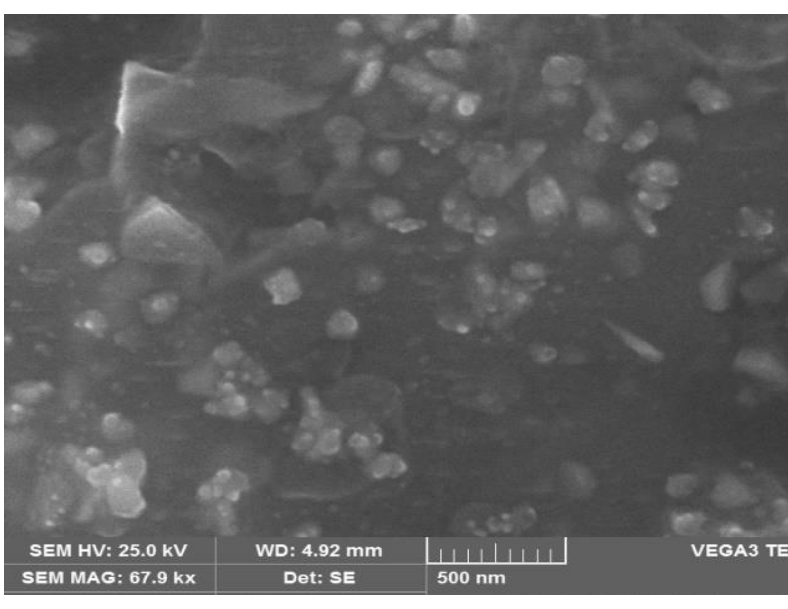

Picture of AgNPs from SEM analysis

\section{XRD analysis:}

From the XRD (X - ray diffraction) the pattern of the obtained AgNPs is shown in Figure. The broadness of the peaks from the XRD pattern can be used to calculate the average crystalline size(D) of the AgNPs using the Scherrer's formula D $=\kappa \lambda / \beta \cos \theta$, where, $\kappa$ is constant $(0.9)$ value known has shape factor, $\lambda$ is the wavelength of the $\mathrm{X}$ rays (1.5406), $\beta$ is FWHM (full width at half maximum) of the diffraction peaks and is the diffraction angle, $\theta$ is the Bragg angle $=2 \theta / 2$

The average crystalline size of the AgNPs calculated using Scherrer's formula is between the range of $10 \mathrm{~nm}$ to $30 \mathrm{~nm}$.

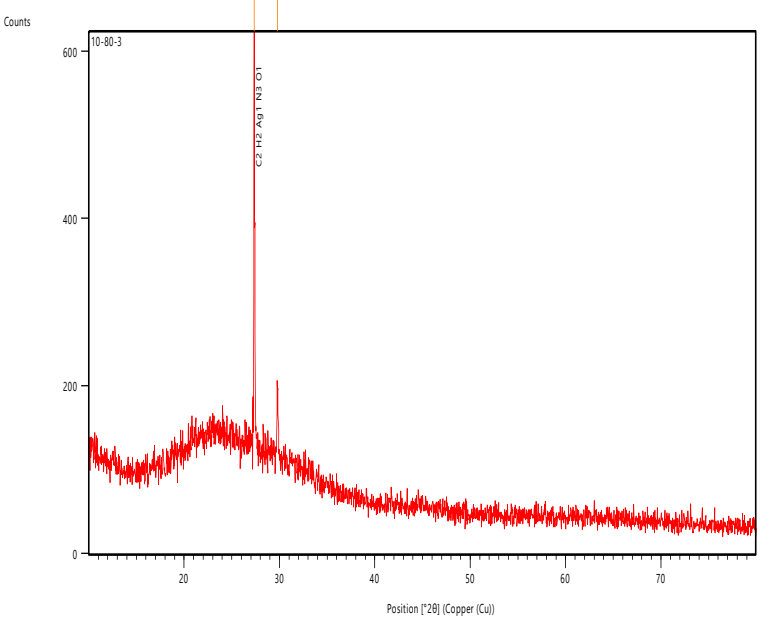

Figure of pattern obtained from XRD analysis

\section{Antimicrobial activity of synthesized AgNPs:}

The antimicrobial or antibacterial potency of the obtained AgNPs was checked against Escherichia coli, Pseudomonas, Staphylococcus, Bacillus and Klebsiella. The zone of inhibition was observed and the diameter of the zone of inhibition was tabulate as follows;

\begin{tabular}{|l|l|l|l|l|l|}
\hline ORGA & $\begin{array}{l}\text { Kleb } \\
\text { NISM }\end{array}$ & $\begin{array}{l}\text { Staphyl } \\
\text { siell } \\
\text { ococcus }\end{array}$ & $\begin{array}{l}\text { E } \\
c \\
\text { ol } \\
i\end{array}$ & $\begin{array}{l}\text { Bac } \\
\text { illu } \\
\text { S }\end{array}$ & $\begin{array}{l}\text { Pseudo } \\
\text { monas }\end{array}$ \\
\hline DIAM & & & & & \\
ETER & & 12 & 2 & 15 & 10 \\
OF & 19 & 12 & 1. & & \\
ZONE & & & 5 & & \\
OF & & & & & \\
INHIB & & & & & \\
ITION & & & & & \\
(IN & & & & \\
mm) & & & & & \\
\hline
\end{tabular}

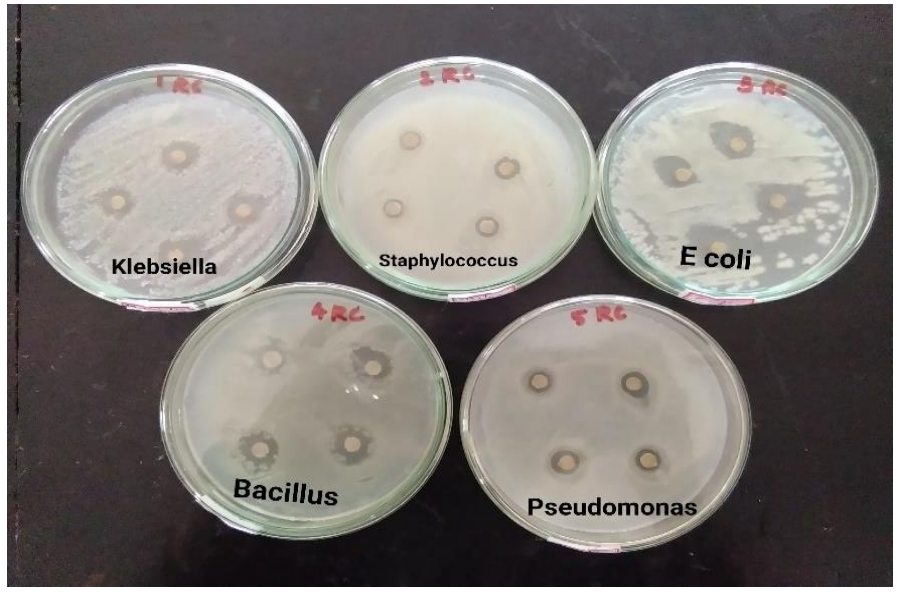

The plates showing zone of inhibition due to antibacterial activity of AgNPs

\section{DISCUSSION}

In this experiment, the green synthesis method was employed to synthesize AgNPs using roasted Coffea arabica bean extract as the bio-reductant. The extract had efficiently reduced the silver ion to silver nanoparticles which was observed as there was change in the color of the solution (extract $+\mathrm{AgNO}_{3}$ ) from brown to blackish brown within 20 minutes. The UV spectrophotometer analysis of these synthesized AgNPs shows its SPR zone and the maximum absorbance was observed at $240 \mathrm{~nm}$ whereas, the project conducted Dhand Vivek et.al., (2015), the maximum absorbance was observed at $447 \mathrm{~nm}$.

Further the silver nanoparticles were characterized by SEM and XRD analysis. SEM study revealed particles having size in the range of $25-51 \mathrm{~nm}$ and shapes was observed as oval and spherical; the experiment conducted by Dhand Vivek et.al., 


\section{International Journal of Engineering Applied Sciences and Technology, 2021 \\ Vol. 5, Issue 11, ISSN No. 2455-2143, Pages 299-303 \\ Published Online March 2021 in IJEAST (http://www.ijeast.com)}

(2015), the particle size of AgNPs was ranging between 3 to $20 \mu \mathrm{m}$ and the particles showed polymorphic shapes like: rocky, flake type, spherical, ellipsoidal and few irregular granules.

XRD pattern showed peak at $27.5^{\circ}$ and $30^{\circ}$ indicating the crystalline nature of the reduced silver nanoparticles with size ranging between $10 \mathrm{~nm}$ to $30 \mathrm{~nm}$. In the experiment conducted by Dhand Vivek et.al., (2015), the XRD patter showed peaks at $38^{0}$.

The antibacterial effect of the synthesized AgNPs was studied on 5 different organisms by disc diffusion method. Klebsiella, Staphylococcus aureus, Escherichia coli, Bacillus and Pseudomonas produced zone of inhibition of $19 \mathrm{~mm}, 12 \mathrm{~mm}$, $21.5 \mathrm{~mm}, 15 \mathrm{~mm}$ and $10 \mathrm{~mm}$ respectively. The maximum inhibition was observed against Escherichia coli i.e., 21.5 thus, showing more efficiency of antimicrobial activity against $E$ coli

\section{CONCLUSION}

From this project conduct on the synthesis of AgNPs by green synthesis method using the extract of Coffea arabica, it can be said that the green synthesis approach of nanoparticle synthesis is advantageous over chemical and physical methods as it is an easy, extremely low energy based, an economic process, doesn't involve any kind of hazardous chemical reagents for reduction and processing thus, an environmentally friendly method. The characterization of the synthesized AgNPs gave the morphological information of the AgNPs.

The antimicrobial or antibacterial activity test was carried out to know the antibacterial property of the synthesized AgNPs against five test organisms i.e., Klebsiella, Staphylococcus aureus, Escherichia coli, Bacillus, and Pseudomonas which are pathologically important, showed zone of inhibition for all the organisms. Hence, AgNPs can be used as drug against both gram positive (from Bacillus and Staphylococcus results) and gram negative (from Escherichia, Klebsiella and Pseudomonas results) organisms. AgNPs kill bacteria through various mechanisms likewise: 1. adhesion to the cell membrane (alteration the membrane structure and permeability; leakage of cellular content and ATPs; impair transport activity), 2. Penetration inside the cell and nucleus (mitochondrial dysfunction; destabilize and denature proteins; destabilize ribosomes; interaction with DNA), 3. cellular toxicity and ROS generation (oxidize proteins and lipids; oxidize DNA bases) 4. Modulation of cell signaling (alteration of phosphotyrosine profile). The large surface area of AgNPs allows them to be in better contact with microorganisms and thus, impart good antibacterial activity even at lower concentrations.
Due to these antibacterial properties the AgNPs have various applications like: incorporation into or on the surface of products like cleaning sprays, skin creams, ATM buttons, and sports clothing etc.

\section{ACKNOWLEDGEMENT:}

The success and final outcome of this project required lot of guidance and assistance from many people and I am extremely privileged to have got this all along the completion of my project. All that I have done is only due to such supervision and assistance and I would not forget to thank them. I respect and thank Dr. Kavitha. B, Assistant professor HOD of Department of Microbiology, for providing me an opportunity to do the project work in MSc II semester and giving all support and guidance which made me complete the project duly. I am extremely thankful to her for providing such a nice support and guidance, although she had busy schedule managing the corporate affairs. I owe my deep gratitude to our guide Dr. Anisa Athar assistant professor who took keen interest on our project work and guided us all along, till the completion of our project work by providing all the necessary information for developing a good system. I would like to extend my gratitude to Mr. Shivaraj Kumar Assistant professor Department of Chemistry, for their suggestions and guidance. I would like to thank Mr. Rajesh of BMS Engineering College for his help in characterization of silver nanoparticles (SEM and XRD). I am thankful to and fortunate enough to get constant support and guidance from all teaching staff of Department of Microbiology, Government Science College which helped us in successfully completing our project work.

\section{REFERECNCE}

1. Dhand Vivek et.al., (2015). Green synthesis of silver nanoparticles using Coffea arabica seed extract and its antimicrobial activity, Center of nanoscience and technology, ISTI, JNTUH, Hyderabad, 500085 AP, India. 10.1016/j.msec.2015.08.018

2. Shukla M K, Singh R P, Reddy C.R.K., Jha B (2012). Synthesis and characterization of agarbased silver nanoparticles and nanocomposite film with antibacterial applications. 10.1016/j.biortech.2011.11.092.

3. Kathiravan et.al., (2014). Synthesis of nanoparticles from Melia dubia leaf extract. 10.1016/j.saa.2014.03.107

4. Rauwel Protima, Küünal Siim, Ferdov Stanislav, and Rauwel Erwan (2014). Green synthesis of silver nanoparticles and their morphologies studied via TEM. https://doi.org/10.1155/2015/682749 
5. Ch. Prasad, Ponneri Venkateshwarlu. (2014). Soybean seeds extract based green synthesis of silver nanoparticles. Indian Journal of Advances in Chemical Science 2(3) 208-211

6. Chandran S.P, Chaudhary M, Pasricha, R, Ahmad A and Sastry M, (2006) Synthesis of gold triangles and silver nanoparticles using aloevera plant extract Biotechnol. Prog., 22, 577-583

7. Rai Mahendra, Yadav Alka and Gade Anket (2009) Silver nanoparticles as a new generation of antimicrobials, Biotechnol. Adv., 2, 76-83

8. Zuorro Antonio et al., (2017). Production of silver nanoparticles by spent coffee ground extracts.

10.21767/2471-9889-C1-002

9. Wang Mengmeng et al., (2017). Antimicrobial and catalytic activity of biosynthesized silver nanoparticles prepared by using an aqueous extract of green coffee bean as reducing agent. 10.1039/C6RA27706C

10. Kim J.S, Kuk E, Yu K.N et al., (2007) "Antimicrobial effects of silver nanoparticles," Nanomedicine:

Nanotechnology, Biology, and Medicine, vol. 3, no. 1, pp. 95-101.

11. Gajbhiye M, Kesharwani J, Ingle A, Gade A, Rai M (2009) Fungus-mediated synthesis of silver nanoparticles and their activity against pathogenic fungi in combination with fluconazole. Nanomed: Nanotechnol Biol Med $5: 382-386$

12. Adams FC, Barbante C. (2013) Nanoscience, nanotechnology and spectrometry. Spectrochim Acta Part B.; 86:3-13. https://doi.org/10.1016/j.sab.2013.04.008

13. Jain N, Bhargava A, Majumdar S, Tarafdar GC, Panwar J (2011) Extracellular biosynthesis and characterization of silver nanoparticles using Aspergillus flavus NJP08: a mechanism perspective. Nanoscale 3:635 